\title{
COMPOSITION OF THE LUNAR HIGHLANDS: POSSIBLE IMPLICATIONS FOR EVOLUTION OF THE EARTH'S CRUST
}

\author{
Paul D. Lowman Jr. \\ Goddard Space Flight Center \\ Greenbelt, Maryland
}

\begin{abstract}
This paper analyzes the possible implications of the composition of the lunar highlands for the origin of terrestrial continents and ocean basins. The highlands probably correspond chemically to ultrabasic, basic, or intermediate to acidic igneous rocks. If they are dominantly ultrabasic or basic, this would imply that the terrestrial continental crust may be essentially sedimentary in origin. However, evidence from various Precambrian studies indicates that the rate of continental growth by island and accretion is so slow that five billion years would not be enough time for the continents to attain their present size and thickness. An alternate implication is that the continents are derived from the mantle by some igneous process related to formation of the earth's core in early Precambrian time. A third possibility is that the continents are meteoritic additions to the earth, and that these supposed bodies missed the moon.
\end{abstract}

A basic lunar highland composition would imply that the lower continental crust layer and the main oceanic crust layer may be the original or nearlyoriginal basaltic crust of the earth. 
Intermediate to acidic lunar highlands would imply, first, that magmas of this composition can be generated by purely igneous processes in the earth's mantle. This in turn would suggest that a sialic crust formed early in the earth's history, and that subsequent continental evolution has been mainly vertical accretion and reworking of this proto-continent. In addition, the probability that the moon was at one time nearly covered with a highland-type of crust would imply, if the highlands are chemically like the earth's continents, that theories of ocean basin growth rather than continental growth should be re-examined. Possibilities discussed include basification by basaltic lava flows, foundering and subcrustal transport of continental crust, removal of part of the primitive crust by fission of the earth to form the moon, and disruption of the primitive crust by asteriod impacts.

\section{INTRODUCTION}

Comprehensive information on the aggregate chemical composition of the lunar highlands should become available within a few years. This knowledge will have major implications for the evolution of the earth's crust, and specifically for the origin of continents and ocean basins. The purpose of this paper is to summarize the possible terrestrial implications of a wide range of highland compositions.

The term "lunar highlands" will be used here to mean the densely-cratered pre-mare terrain with relatively high albedo $(0.10$ to 0.15$)$ typical of the southern part of the earthward hemisphere and most of the far hemisphere. Although this usage is essentially conventional, certain parts of the relatively high-albedo terrain are excluded: the Imbrium-Serenitatis Mountains, and the areas surrounding Mare Crisium, Mare Humorum, Mare Nubium, and Mare Muscoviense. 
The reason for this is that these areas may be underlain by ejecta from the mare basins (Hackman, 1966; McCauley, 1967), and hence would be partly derived from considerable depth.

The composition of the lunar highlands probably resembles known varieties of igneous rock or stoney meteorites, judging from the moon's mean density, estimates of cosmic elemental abundances, photometry, and spacecraft investigations, although as Walter (1965) points out, magmatic differentiation in the moon may have produced more siliceous end-products. Possible compositions will be discussed under three main categories:

(1) Ultrabasic (ultramafic) $-\mathrm{SiO}_{2}$ about $44 \%$, high iron and magnesium content, corresponding chemically to peridotite, dunite, serpentine, chondritic meteorites, or "pyrolite," (Ringwood's (1962) hypothetical upper mantle material, equivalent to a $3: 1$ dunite: basalt mixture).

(2) Basic (mafic) - $\mathrm{SiO}_{2}$ about $50 \%$, corresponding chemically to basalt, eclogite, gabbro, or achondritic meteorites.

(3) Intermediate to acidic (sialic) - $\mathrm{SiO}_{2}$ about $55 \%$, corresponding chemically to andesites, dacites, rhyolites, or their plutonic equivalents, or to more siliceous rocks.

The assumption that the lunar highlands are homogeneous enough to be categorized thus is of course open to question. It is based primarily on the fact that major crustal divisions of the earth can be classified chemically in about the same way, despite the tremendous variety of rock types present - one whole class of which, the water-laid sedimentary rocks, will probably be absent on the moon. Furthermore, as will become apparent, much of the reasoning presented 
here is based on the absence of certain rock types on the moon, and hence does not depend on its homogeneity.

It should be pointed out, although not vital to the discussion, that the interior of the moon can reasonably be assumed to consist of the chemical equivalent of some variety of ultrabasic rock. In addition to the mean density, the evidence that the maria are apparently basalt, from Surveyor spacecraft experiments (Turkevich, et al, 1967) and photometry (Hapke, 1968), points in this direction because of the wide variety of field and laboratory evidence that basaltic magmas are formed by partial fusion or differentiation of such material. It is conceivable that the inside of the moon might be eclogite, which could also give rise to basaltic liquid by complete melting (Yoder and Tilley, 1962). However, the more recent studies of Ringwood and Green (1966), indicating that eclogite is thermodynamically stable throughout the continental crust, appear to contradict the phase change theory for the Mohorovicic discontinuity in the earth and by implication for the interior of the moon as well.

A structure in which an interior of chondritic material is overlain by carbonaceous chondrites, a consequence of Mason's (1962) theory for the origin of chondrites, appears possible; whether the results of Lunar Orbiter tracking (Lorell and Sjogren, 1968), indicating that the moon is nearly homogeneous, rule it out remains to be seen.

Gast (1968) has pointed out that the Surveyor V results indicating a basaltic mare composition do not necessarily indicate differentiation of the moon. This possibility, though real, does not appear to weaken the approach followed here 
for two reasons. First, there is considerable independent evidence that the mare material is true, internally-generated, volcanic rock or ash:

(1) the unambiguous demonstration (Shoemaker, 1964) that emplacement of the mare material occurred some time after the formation of the mare basins (i.e., it is not impact breccia related to the presumed impact formation of the mare basins);

(2) the occurrence of mare material in large areas, such as Oceanus Procellarum and Mare Frigoris, which are not mare basins in the usual sense;

(3) the many flow-like features visible in the maria on high-resolution Lunar Orbiter and Surveyor photographs.

Second, the two chemical types discussed by Gast - the Surveyor V mare material and the eucrites - although perhaps significantly different from terrestrial basalts, are still clearly related to basic rocks rather than to the ultrabasic or acidic to intermediate rocks.

\section{ULTRABASIC COMPOSITION}

There are several possible implications for the origin of continents if the lunar highlands are ultrabasic. The problem in that case would be to explain why the moon has no sialic crust as does the earth.

1. The terrestrial continental crust may be essentially sedimentary in origin, in that it has been formed, over geologic time, largely by geosynclinal sedimentation and associated igneous activity.

This possibility is at first glance the most attractive; it is in agreement with a popular school of thought on continental growth (Engel, 1963), and depends 
on the most obvious difference between earth and moon, namely the presence of an atmosphere and hydrosphere. However, there are a number of serious weaknesses in the theory of lateral continental growth by geosynclinal accretion as proposed by, for example, Kay (1951) and Wilson (1954):

a. The recent discovery that Precambrian rocks with ages of 2 to 3.5 billion years underly much of North America (Muehlberger, et al, 1967), and probably other continents indicates strongly that the accretion has been as much vertical (i.e., from the mantle) as horizontal.

b. The existence of granite paragneisses and quartz-bearing sediments more than 3.4 billion years old implies that a sialic crust from which they were derived existed before that time (Donn, et al, 1965).

c. There are few if any clear-cut examples of formation of continental crust from oceanic crust by ensimatic geosynclinal accretion. The Western Hemisphere Cordillera has been considered such an increment, but this concept has recently been challenged explicitly and implicitly. In a study of the Canadian Rockies, Roddick, et al, (1967) concluded that". . . simple westward accretion of the continent has not been appreciable since Paleozoic time." Dickinson (1962) arrived at a similar conclusion on the basis of petrographic and chemical investigations of andesites from the western United States, finding no evidence of a fundamental change in the composition of the underlying crust since mid-Paleozoic time. This, he suggested ". . challenges the concept that the widespread sialic plates of the modern continents grew from much smaller embryonic cores as orogenesis welded successive geosynclinal belts to the adjacent continental margins. . .". Finally, a recent collection of papers 
covering the geology of the Cordillera (Childs and Beebe, 1963), including eleven which specifically discussed the evolution of all parts of the chain from Antarctica to Alaska, did not contain a single suggestion that any part of the present mountain belt was an ensimatic accretion to any of the three continents.

d. The thickness of the sialic part of the continental crust (that above the Conrad discontinuity, where located, or with P-wave velocities of about 5 to 7 kilometers per second) ranges from roughly 15 to 25 kilometers in most parts of the world (Gutenberg, 1960; Holmes, 1965; Bateman and Eaton, 1967). This alone suggests that igneous and metamorphic rocks exposed at the surface were not deposited directly on the oceanic crust. The argument is reinforced by the probability that the batholithic rocks and metasediments (frequently of granulite facies) now exposed were probably formed in the lower portions of the former geosynclines (although the igneous rocks have probably moved upward); if so, much of the crustal thickness below them must be the pre-existing continental crust on which the geosyncline was formed. A single cycle of geosynclinal sedimentation and vulcanism, then, probably can not produce the entire thickness of continental crust present in most places. (For a specific example, see Lowman, 1964.)

The theory that continents grow by successive geosynclinal-volcanic cycles can not, of course, be discarded yet. A recent paper describing the Sierra Nevada batholith, by Bateman and Eaton (1968), provides an exceptionally clear picture of how the process may take place. However, their description leads to a most 
interesting corollary to the theory of geosynclinal continental growth. Assuming the Sierra Nevada batholith and adjacent areas to represent an ensimatic addition to the continent, we see that it has taken about 400 million years or more to increase the width of North America, at that latitude, less than $8 \%$. (This estimate includes the batholith and land westward to the Pacific coast, and does not include the eastern continental shelf.) If North America has grown at this rate through geologic time, on the order of 5 billion years must have been necessary to reach its present size. Radiometric dates, of course, can be interpreted (e.g., Engel, 1963, Fig. 9) as showing that the growth rate has at times been considerably greater. However, Gastil (1960) has demonstrated that such concentric date patterns do not necessarily represent successive continental accretions, but perhaps only a successive outward migration of instability. His argument is strengthened by the evidence previously cited that most exposed plutonic metasediments were formed on a pre-existing continental crust.

It seems likely that geosynclinal sedimentation would not, under any theory of the earth's origin, have started until a few hundred million years after formation of the earth. Therefore, it appears that present estimates of 4.7 billion years for the age of the earth do not provide enough time for continental growth by this process. If the continents are essentially sedimentary aggregates, as may be implied by an ultrabasic lunar crust, a corollary is that the earth is considerably more than 5 billion years old. Judging from the width and age of the supposed increment represented by the Sierra Nevada batholith and associated eugeosynclinal rocks, and allowing time for the earth to begin sedimentary processes after its formation, an age of around 6 billion years would not appear excessive. 
2. The continental crust may be essentially igneous in origin, and related in some way to formation of the earth's core.

This possiblity is suggested by another obvious difference between the earth and the moon, namely the earth's large iron core. (The phase-change theory for the core can probably be safely disregarded (Birch, 1965)). There has been relatively little investigation of what effect core formation might have had on early continental crust formation, except for papers by O'Keefe (1966) and Elsasser (1963). Also, there is disagreement on whether the core was formed rapidly early in earth history or gradually through geologic time (Urey, 1960). However, if core formation was early and rapid, it seems likely that this would have had major effects on early continent formation. Birch (1965) points out that it would have been strongly exothermic, as the gravitational energy of the iron became converted to heat during differentiation, raising the temperature of the earth some $2000^{\circ}$. (The differentiation process would have had to remove this excess heat, since known sources can nearly account for the observed heat flow (MacDonald, 1959).

Although the details of such a process are not at all clear, it would appear that core formation might have facilitated early crustal differentiation in several ways:

1) Internal temperatures would have been greatly raised throughout the mantle;

2) Pervasive fracturing, though short-lived at depth, would have occurred;

3) Major asymmetry in the structure and composition of the mantle might result if the core differentiated in several large drops (Elsasser, 1963; 
Birch, 1965), producing the uneven distribution of continental crust.

The segregation of the core might have thus promoted partial melting of the mantle to depths of several hundred kilometers. Whether intermediate to acidic magmas would be generated is not certain, but if the mantle consisted of "pyrolite," it seems quite possible, especially since there is considerable evidence that intermediate magmas are presently being formed in the upper mantle (Taylor, 1967).

The suggestion that core formation started and localized development of the continental crust has several attractions. If Elsasser's concept of settling of the liquid iron in very large drops is correct, the fact that the earth is not covered with continental crust is more easily understood. Furthermore, if core formation was essentially completed early in the earth's history, the reason large quantities of intermediate to acidic magmas are not being presently generated in the suboceanic mantle becomes clear. The main weakness in the hypothesis is chiefly lack of knowledge rather than contradictory facts; further discussion at this stage seems unprofitable.

3. The continental crust may have been formed by igneous processes originating in the deep mantle.

The mechanism proposed by Matsumoto (1965) forms the basis for this inference. Matsumoto suggested, on the basis of study of the $\mathrm{MgO}-\mathrm{SiO}_{2}-\mathrm{CaMgSi}_{2} \mathrm{O}_{6}$ system at high pressures, that intermediate to acidic magmas might form by partial melting or crystallization differentiation at depths greater than 300 kilometers (pressures over $89 \mathrm{~kb}$ ) in the earth's mantle. He further suggests 
convective overturn as a means of bringing this calcalkaline material to the upper mantle, where it could become emplaced in the crust as batholiths or erupted.

Lunar geologic evidence can unfortunately not be applied directly to evaluation of this theory, because maximum pressures in the moon (around 50,000 bars) correspond to depths of only 2-300 kilometers in the earth. However, since the process proposed by Matsumoto depends on high pressures unique to the earth, the absence of sialic rocks on the moon would tend to support it to a degree.

4. The continents may have been initially formed by infall of large bodies with sialic compositions.

This theory has been proposed most recently by Alfvén (1963) and Donn, Donn, and Valentine (1965); the latter present convincing geologic evidence that much of the continental crust is at least 4 billion years old, and that if the earth is 4.5 billion years old, there has not been time for proposed differentiation mechanisms to produce this amount of crust. An ultrabasic composition for the lunar crust might provide some support for this hypothesis, since it could be argued that comparable sialic meteorites, whose number must have been fairly low to account for the sporadic distribution of continents, simply missed the moon. However, the ad hoc nature of this argument makes it unattractive. An evaluation of the theory of Donn, et al, would be out of place here, but it is clear that if the moon has a largely ultrabasic crust, it can not be one of the supposed meteoritic bodies like those from which the continents were formed, as proposed Donn, et al. 


\section{BASIC COMPOSITION}

Photometric pre-Surveyor studies by Hapke (1968), as well as the Surveyor VII results reported by Turkevich in 1968 , indicate that the lunar highlands have about the same composition as the maria, and are basaltic. Although the geomorphology of the highlands is obviously very different from that of the maria, it is likely that, if basaltic, they were ultimately derived, like the maria, from the interior of the moon by partial melting. A basaltic composition for the highlands can reasonably be interpreted as meaning that the crust of almost the entire moon (part of which is now flooded by later basalts) is like the sub-oceanic or lower continental crust of the earth (with P-wave velocities of about 6.5 to $7.5 \mathrm{~km} / \mathrm{sec}$ (Holmes, 1965)), generally though to be basalt, gabbro, or amphibolite. This would have the following possible implications.

1. The lower layer of the continental crust (so far neither distinguishable nor divisible from a similar layer of the oceanic crust) may be of basaltic composition, and is the original or nearly-original crust of the earth. The Mohorovicic discontinuity in that case might be the primordial surface onto which the basalts were erupted.

It is hardly necessary to mention that most authorities already consider this layer to be gabbro or basalt: see, for example, Poldervaart (1955), Gutenberg (1960), and Kuno (1967). (Ringwood and Green (1966) suggest an intermediate composition.) However, the inference that it is the original crust of the earth in the ocean basins directly contradicts current thinking on the age and origin of the ocean floor. Virtually all the information collected since World War II in the form of bottom samples and radiometric, paleontologic, and remnant magnetism studies indicates that the ocean basins are not much older than Cretaceous. 
Recent paleomagnetism investigations (Vine, 1966), moreover, have given considerable support to the sea-floor spreading concept proposed by Hess (1962) and Dietz (1961), and indirectly to the mantle convection current theory which holds the ocean floors to be the tops of convection cells. Therefore, some discussion of the inference that the basaltic layer could be the primordial crust is necessary. There are two main lines of reasoning.

a. The upper mantle and the moon probably have similar compositions, since their mean densities are similar, and both have evidently produced large quantities of basaltic magma. The earth is demonstrably more internally active than the moon, and it therefore seems likely that if the moon developed an all-encompassing basaltic crust, the earth should have too. (The converse reasoning, that the moon has developed a basaltic crust, is presented by Mc Connell, et al (1967.)

b. Simple superposition dictates that the basaltic layer of the continental crust should be older than the granitic layer, which, as pointed out previously, is 3 to 4 billion years old in large areas. The possiblity that the basalt is younger, i.e., is intrusive, seems definitely contradicted; there are no known basalt batholiths, and the intrusion of some 5 kilometers of basalt under the thin oceanic sediment layer seems physically unlikely, quite apart from the demonstrably post-Cretaceous age of most oceanic sediments. (This does not, of course, exclude the possiblity of young, relatively thin intrusives or flows in the oceans; the argument is that much or most of the "basaltic" layer would be ancient.) 
2. The continental crust may be essentially sedimentary in origin, in that it has been formed largely by geosynclinal sedimentation and attendant metamorphism and crustal magma generation.

This inference is of course the same as that discussed previously for an ultrabasic composition; the relative thinness and chemical composition of the continental "basaltic" layer make it unlikely that the "granitic" layer was formed largely by weathering, erosion, and attendant processes from it. A complex cycle of geosynclinal sedimentation and volcanism such as already discussed would be necessary to convert oceanic to continental crust.

It should be pointed out here that the continental crust above the Conrad discontinuity can not be, to any large degree, the result of partial melting or magmatic differentiation of the basaltic layer. Although this is petrologically possible (Tuttle and Bowen, 1958) and even likely on a small scale, partial melting of the basaltic layer would produce something like $10 \%$ of its volume in intermediate to acidic magmas; a basaltic layer on the order of $200 \mathrm{~km}$ thickness would therefore be required to generate the observed granitic layer.

3. The continental crust may be essentially igneous in origin, and related in some way to formation of the earth's core.

This inference is also similar to that for the ultrabasic case; since crustal differentiation caused by core formation would be primarily a mantle phenomenon, the presence of a basaltic crust would probably have little effect. 
4. The hypothesis that the continental crust is a meteoritic addition to the earth can probably be rejected if the moon's crust is chiefly basalt.

The reasoning here depends on the assumption that the lower continental crustal layer (basaltic layer) is essentially the same as that underlying the ocean basins (see, for example, Bateman and Eaton (1967), Fig. 4). Such continuity would not be expected if the continents were the much-modified remains of sialic asteroids; even though it can be reasonably argued that low velocity impacts might cause fusion and mixing of these bodies with the crust, it would certainly be expected that they would create large (though shallow) craters, thus disrupting the original basaltic crust. The effects of major impacts are considered (Lowman, 1967) by many authorities to be observable in lunar mare basins such as Mare Imbrium and Mare Oriental; the resulting structure is similar except for size to that of much smaller craters such as Copernicus, and it is clear that the infalling body does not simply plaster itself onto the moon.

\section{INTERMEDIATE TO ACIDIC COMPOSITION}

Verification of a sialic composition for the lunar highlands would be perhaps the most decisive discovery in its implications for the evolution of the earth and for igneous petrology. Before discussing these, a few fundamental problems should be clarified.

First, there is still uncertainty as to what rock type the continents correspond to chemically. The older view, that the continents were mainly "granite," (e.g., Daly, 1926, p. 94) has become modified as more information is collected (Pakiser and Robinson, 1966). Poldervaart (1955) considered granodiorite $\left(\mathrm{SiO}_{2}\right.$ about $66 \%$ ) to best represent the upper continental layer. A recent comprehensive 
program of sampling on the Canadian shield by Eade, Fahrig, and Maxwell (1966) tends to confirm this; the average calculated composition of 200,000 square miles was $65.8 \% \mathrm{SiO}_{2}$. These estimates obviously refer to the upper part of the crust; the average composition of the entire continental crust above the Mohorovicic discontinuity would be considerably more basic if the lower part is chemically basaltic.

In addition to this uncertainty, there are other difficulties in attempting to categorize the continents as intermediate or acidic:

1. Large intrusive bodies such as the Sierra Nevada batholith are gradational, consisting of rocks ranging from quartz diorite to granite.

2. Many granite bodies appear to have been generated within the crust, probably from andesites (Dickinson, 1962; Taylor, 1967). The reverse is obviously not true, for petrologic reasons.

3. Both andesites and granites are largely peculiar to the continents or to continental borders (with the exception of occurrences such as Macquarie Island (Gilluly, 1955) and Iceland).

For these reasons, there will be no attempt here to separate the intermediate and acidic rocks in discussing the implications of lunar highland compositions for the origin of continents and ocean basins. These appear to be the following. 1. Large volumes of intermediate to acidic magmas can form by purely igneous processes from material similar to the upper mantle of the earth.

This follows from the assumption, accepted by almost all geologists who have studied the moon, that the moon has not possessed a sensible atmosphere 
for a geologically significant time. If this is so, then granite-forming processes such as anatexis and probably metasomatism can be ruled out, since they involve geosynclinal sedimentary rocks, which would not exist on the moon. However, classical differentiation of basaltic magmas (Bowen, 1928) can probably also be ruled out for the production of the lunar highlands for the same reasons it was discarded for terrestrial batholiths, chiefly the apparent absence of the enormous complementary volumes of basalt necessary. (The maria are largely younger than the highlands and have much less total volume.) Therefore, a sialic lunar crust would probably be formed by partial melting of the interior, which, as discussed previously, is probably similar to the upper mantle. (For evidence that sialic magmas form in the earth's mantle, rather than in former geosynclines, see Hamilton and Myers, 1967.)

2. A sialic crust probably formed early in the earth's history, and comprised the platform indicated by various Precambrian investigations summarized by Donn, Donn, and Valentine (1965).

The reasoning here is that already described in relation to basalts, namely that if the moon's interior and the upper mantle are similar, any major igneous fractionation taking place in the moon should have also occurred in the earth. The main corollary to this inference is that continental evolution since early Precambrian time has been chiefly a matter of re-working of this fundamental platform, with possible minor lateral accretion by means of ensimatic eugeosymclines and a subordinate though substantial degree of vertical accretion of basalts, andesites, and rhyolites and their sedimentary derivatives. Apparent examples of continental growth by geosynclinal activity at continental borders 
would be, as implied by Dana (1847) and Donn, et al (1965), the result of continents rather than their cause.

The discovery that the lunar highlands were largely sialic rock would obviously give considerable weight to theories of continental growth depending, explicity or implicitly, on sub-crustal igneous processes for the formation of intermediate to acidic magmas. Such theories have been proposed by Hurley, et al, (1962), Ringwood and Green (1966), and Taylor (1967). All these authors have produced evidence that sialic magmas are generated in the mantle, and conclude that the continents are therefore fundamentally of internal origin. However, all mechanisms proposed are long-term, multi-cycle processes by which the continents have grown through geologic time. A sialic lunar crust would thus not support these theories, because there is no evidence in crater distribution that the lunar highlands have grown in stages corresponding to continental accretion. However, there is considerable evidence in the Lunar Orbiter photographs of repeated vulcanism in the highlands; extensive radiometric studies of the lunar surface will probably be necessary to settle the problem.

3. The present two-fold division of the earth's crust into continental and oceanic segments is the result of formation of ocean basins rather than of continental growth.

This inference rests, first, on the assumption that the lunar highlands as defined here are reasonably homogeneous chemically and second, that they once formed the entire surface of the moon, having later subsided under eruptions of mare basalts (Von Bulow, 1967). The second assumption is somewhat betterfounded that the first; even if they were initiated by impact, the mare material 
and the mare basins are clearly older than the highlands (except for possible isolated extrusions, such as the Flamsteed ring (O'Keefe, et al, 1967). Moreover, all stages between complete burial by mare material and incipient subsidence are visible in regions such as Mare Nectaris and Oceanus Procellarum. It would be expected that if the moon developed an all-encompassing crust of sialic composition, the earth did too. The question which must then be answered is of course why only about $1 / 3$ of the earth's surface is occupied by sialic crust. There are three main theories which would require serious consideration should the lunar highlands be sialic.

a. The earth's crust may be undergoing secular "basification," to use the term of Beloussov and Ruditch (1961) for enlargement of the oceanic crust by basaltic eruptions which collapse and assimilate the granitic continental crust (see also Ramberg, 1964). Beloussov (1962) in fact proposes that this process is precisely analogous to the evolution of the moon's crust by subsidence and basaltic eruptions. Although the basification theory as applied to the earth by Beloussov is open to criticism (depending in part, for example, on the phase-change explanation for the Mohorovicic discontinuity), it would clearly be strengthened by verification of a sialic composition for the lunar highlands. The theory proposed by Ringwood and Green (1966), although intended to explain the formation of continents and calc-alkaline magmas, is of interest as a possible basification mechanism. They suggest that masses of eclogite, derived from basalt piles, might sink into the mantle because of their greater density, there undergoing partial melting to produce calcalkaline magmas. If, for some reason, the last process should not take 
place, the net result would be conversion of continental to oceanic crust rather than the reverse. There is some evidence that this has happened in, for example, western India, where the Deccan basalts appear to have foundered (Holmes, 1965, p. 1224). Whether eclogite foundering could occur in the moon, in view of the lower force of gravity, is open to question.

b. Reorganization of the terrestrial continental crust may be occuring by means of mantle convection currents, as proposed by Gilluly (1955, 1963). Gilluly suggests that sial must be added to the continents somehow to make up for losses to the ocean by erosion, and that the mechanism might be convection currents which carry sial from foundered borderlands under the continents. A problem with this interpretation is that demonstration of the existence of large amounts of sial on the moon would tend to remove one of the bases for Gilluly's suggestion, namely that the existing continental crust could not generate the volumes of sialic rock observed in large batholiths; the latter might then be generated in the mantle.

c. The missing continental crust might have been removed, with part of the mantle, during the fission of the earth to form the moon, as proposed by Darwin (1879), Wise (1963), and O'Keefe (1963). In this case, the lunar highlands would not be simply analogous to the continental crust but a former part of it. The Pacific basin is usually proposed as the scar of separation; if so, the other oceans would have to be accounted for by later processes, such as sea-floor spreading. 
The fission theory for the moon's origin is of course controversial, and can not be discussed in detail here. However, it would appear difficult to account for sialic lunar highlands with this mechanism for the following reasons. First, the fission of the earth after it had attained its present rigidity is open to criticism; Jeffreys (1930), for example, has shown that internal friction would probably damp the supposed resonant bulge before it became very large. However, since the supposed primordial sialic crust would, under any internal mechanism, such as partial melting or fractional crystallization, have been formed only after the earth solidified (if it had been liquid), this inference is subject to all the objections raised by Jeffreys. The possibility that the moon's birth removed a sialic crust while the mantle of the earth was still liquid is unlikely on petrologic grounds; the sialic rocks are the last fraction to form from a magma, not the first, a point generally overlooked by proponents of continental origin as "scum" collected by down-turning convection currents. (This mechanism for initiation of continents was proposed as early as 1847 by Dana, but the nature of late-stage magmatic differentiation was not understood at that time.)

Other criticisms can be made of the theory that the lunar highlands are the missing continental crust. First, no terrain on earth, however old, resembles the lunar highlands morphologically or structurally. Recent terrain photographs of Precambrian areas made from Gemini spacecraft (Lowman, 1968) are notable for the scarcity of possible impact structures. This can be explained by subsequent geological processes. However, the moon shows no global fracture pattern reflecting the tremendous distortion that must have been involved in fission from the earth; Baldwin (1963) points out that most lunar lineaments are radial fractures 
associated with the circular maria, rather than resulting from "settling or expansion of the entire moon." It is clear, therefore, that if the (sialic) lunar highlands are former continental crust, they have been so altered by crater formation and other processes that no visible evidence of their origin remains.

d. The ocean basins might be the site of immense impact events early in the earth's history, which dispersed the continental crust as large ejecta blankets analogous to the Fra Mauro formation ringing Mare Imbrium (Hackman, 1966). This possibility is speculative in the extreme, despite Gilvarry's $(1961,1962)$ demonstration that the ocean basins may be approximated by very large craters. However, since a similar process is thought by many authorities to have formed the lunar mare basins (e.g., Baldwin, 1963), it must still be considered possible for the earth.

\section{SUMMARY AND CONCLUSIONS}

It is clear that, even after the composition of the lunar highlands is better known, it will be difficult to draw unambiguous inferences about the origin of ter restrial continents. Nevertheless, a few general conclusions can be reached even at this time.

First, it appears that if the highlands are of either ultrabasic or basic composition - i.e.. if the moon has no major amount of sialic crust - the existence of continents on the earth must depend on some unique difference between the earth and moon. The most obvious of these, the presence of an atmosphere, points to the continents as essentially sedimentary. However, there are critical weaknesses in the theory of continental growth by geosynclinal accretion; more important, even if the theory is correct, the growth rate appears too slow if the 
earth is no more than 5 billion years old. The most promising alternative is that the origin of continents is in some way dependent on the formation of the core. In summary, then, a dominantly ultrabasic or basic composition for the lunar highlands implies either that the earth is significantly older than 5 billion years, or that the continents were derived by igneous processes from the mantle, probably early in the earth's history.

If the lunar highlands have an intermediate or acidic composition, it would point to an igneous origin for terrestrial continents. More generally, since the maria and highlands would then appear to correspond to the ocean basins and continents, the theory that terrestrial crustal evolution has been primarily a process of ocean basin growth, rather than continental growth, would be strengthened; i.e., it would seem that the earth's crust has become more mafic over geologic time.

The fact that most of these possible inferences are either in direct contradiction to currently popular concepts of crustal evolution and the age of the earth, or suggest essentially new lines of inquiry, strongly indicates the geologic importance of extensive lunar exploration. The desirability of geochemical investigations of Venus is also implied; having nearly the same size and density as the earth, Venus would provide an even more helpful control in comparative planetology. 


\section{REFERENCES}

Engel, A. E. J., Geological Evolution of North America, Science, V. 140, p. 140$152,1963$.

Beloussov, V. V., Basic Problems in Geotectonics, McGraw-Hill, New York, 1962.

Turkevich, A. L., E. J. Franzgrote, and J. H. Patterson, Chemical Analysis of the Moon at the Surveyor V Landing Site: Preliminary Results, pp. 119-149 in Surveyor V Mission Report, Part II: Science Results, Technical Report 32-1246, Jet Propulsion Laboratory, California Institute of Technology, Pasadena, California, 1 November, 1967.

Yoder, H. S., Jr., and C. E. Tilley, Origin of Basalt Magmas: An Experimental Study of Natural and Synthetic Rock Systems, Jour. Petrology, V.3, pp. 342-532, 1962.

Ringwood, A. E., A Model for the Upper Mantle, Jour. Geophys. Res., V.67, pp. 857-867, 1962.

Kay, M., North American Geosynclines, Geol. Soc. America, Memoir 48, 1951.

Wilson, J. T., Chapter 4 in The Earth as a Planet, G. P. Kuiper and B. M. Middlehurst, Editors, U. of Chicago Press, Chicago, 1954.

Muehlberger, W. R., R. E. Denison, and E. G. Lidiak, Basement Rocks in Continental Interior of United States, Bull. Am. Assoc. Petroleum Geologists, V.51, No. 12, pp. 2351-2380, December, 1967. 
Donn, W. L., B. D. Donn, and W. G. Valentine, On the Early History of the Earth, Bull. Geol. Soc. America, V. 76, pp, 287-306, March, 1965.

Childs, O. E., and B. W. Beebe, Backbone of the Americas, A Symposium Memoir 2, Am. Assoc. Petroleum Geologists, Tulsa, Oklahoma, 1963.

Dickinson, W. R., Petrogenetic Significance of Geosynclinal Andesitic Volcanism Along the Pacific Margin of North America, Bull. Geol. Soc. America, V. 73, pp. 1241-1256, October, 1962.

Roddick, J. A., J. O. Wheeler, H. Gabrielse, and J. G. Souther, Age and Nature of the Canadian Part of the Circum-Pacific Orogenic Belt, Tectonophysics, V. 4, 4-6, pp. 319-337, 1967.

Pakiser, L. C., and R. Robinson, Composition and Evolution of the Continental Crust As Suggested by Seismic Observations, Tectonophysics, v. 3, 6, pp. 547$557,1966$.

Gutenberg, B., Physics of the Earth's Interior, Academic Press, New York, 1959.

Holmes, A., Principles of Physical Geology, Second Edition, Ronald Press, New York, 1965.

Bateman, P. C., and J. P. Eaton, Sierra Nevada Batholith, Science, V. 158, pp. 1407-1417, 15 December 1967.

Daly, R. A., Our Mobile Earth, Charles Scribner's Sons, New York, 1926. 
Pakiser, L. C., and R. Robinson, Composition and Evolution of the Continental Crust as Suggested by Seismic Observations, Tectonophysics, V. 3, 6, pp. 547$557,1966$.

Eade, K. E., W. R. Fahrig, and J. A. Maxwell, Composition of Crystalline Shield Rocks and Fractionating Effects of Regional Metamorphism, Nature, V. 211, No. 5055, pp. 1245-1249, Sept. 17, 1966.

Gilluly, J., Geologic Contrasts Between Continents and Ocean Basins, in Crust of the Earth, A. Poldervaart, E., Geol. Soc. America Sp. Paper 62, 1955.

Bowen, N. L., The Evolution of the Igneous Rocks, (Reprint), Dover Publications, New York, 1956.

Bülow, K. von, Lunar Maria Genesis, in The Encyclopedia of Atmospheric Sciences and Astrogeology, R. W. Fairbridge, Ed., Reinhold Publishing Company, New York, 1967.

O'Keefe, J. A., P. D. Lowman, Jr., and W. S. Cameron, Lunar Ring Dikes from Lunar Orbiter I, Science, V. 155, No. 3758, pp. 77-79, Jan, 6, 1967.

Beloussov, V. V., and E. M. Ruditch, Island Arcs in the Development of the Earth's Structure (especially in the region of Japan and the Sea of Okhotsk), Jour. Geology, V. 69, pp. 647-658, 1961.

Ramberg, H., A model For the Evolution of Continents, Oceans, and Orogens, Tectonophysics, V. 1, 2, pp. 159-174, Sept. 1964. 
Gilluly, J., The Tectonic Evolution of the Western United States, Quart. Jour. Geol. Soc. London, V. 119, pp. 133-174, 1963.

Darwin, G. H., On the Precession of a Viscous Spheroid, and on the Remote History of the Earth, Phil. Trans. Roy. Soc., Part II, 170, pp. 447-530, 1879.

Wise, D.U., An Origin of the Moon by Rotational Fission During Formation of the Earth's Core, Jour. Geophys. Res., V. 68, pp. 1547-1554, 1963.

O'Keefe, J. A., Two Avenues from Astronomy to Geology, in The Earth Sciences, T. W. Donnelly, Ed., Rice University, Houston, 1963.

Fielder, G., Lunar Tectonics, in The Encyclopedia of Atmospheric Sciences and Astrogeology, R. W. Fairbridge, Ed., Reinhold Publishing Company, New York, 1967.

Hackman, R. J., Geologic Map of the Montes Apenninus Region of the Moon, Map I-463, (LAC-41), U. S. Geological Survey, Washington, D. C., 1966.

Gilvarry, J. J., The Origin of Ocean Basins and Continents, Nature, V. 190, pp. 1048-1053, 1961.

Gilvarry, J. J., Dimensional Correlation of Lunar Maria and Terrestrial Ocean Basins, Nature, V. 196, pp. 975-976, 1962.

Lowman, P. D., Jr., Tectonic Implications of Precambrian Metasediments in Gilpin County, Colorado (Abstract), Trans. Am. Geophys. Union, V. 45, No. 1, p. 102, March, 1964. 
Birch, F., Speculation on the Earth's Thermal History, Bull. Geol. Soc. America,, V.76, pp. 133-154, Feb. 1965.

Elsasser, W. M., Early History of the Earth, in Earth Science and Meteoritics, J. Geiss and E. D. Goldberg, Eds., North-Holland Publishing Company, Amsterdam, 1963.

O'Keefe, J. A., The Origin of the Moon and the Core of the Earth, in The EarthMoon System, B. G. Marsden and A. G. W. Cameron, Eds., Plenum Press, New York, 1966.

Urey, H. C., On the Chemical Evolution and Densities of the Planets, Geochim. et Cosmochim. Acta, V. 18, pp. 151-153, 1960.

Taylor, S. R., The Origin and Growth of Continents, Tectonophysics, V. 4, 1; pp. $17-34,1967$.

Hapke, B., Lunar Surface: Composition Inferred From Optical Properties, Science, V. 159, No. 3810, pp. 76-79, Jan. 5, 1968.

Poldervaart, A., Chemistry of the Earth's Crust, pp. 119-144 in Crust of the Earth, A. Poldervaart, Ed., Geol. Soc. America Sp. Paper 62, 1955.

Kuno, H., Volcanological and Petrological Evidences Regarding the Nature of the Upper Mantle, Ch. 5 in The Earth's Mantle, T. F. Gaskell, Ed., Academic Press, New York, 1967.

Hess, H. H. History of Ocean Basins, in Petrologic Studies: A Volume in Honor of A. F. Buddington, A. E. J. Engel, H. L. James. and B. F. Leonard, Eds., Geol. Soc. America, 1962. 
Dietz, R. S., Continent and Ocean Basin Evolution by Spreading of the Sea Floor, Nature, V. 190, pp. 854-857, 1961.

Vine, F. J., Sea-Floor Spreading, Science, V. 154, No. 3755, pp. 1405-1415, 1966.

Mc Connell, R. K. Jr., L. A. McClaine, D. W. Lee, J. R. Aronson, and R. V. Allen, A Model for Planetary Igneous Differentiation, Reviews of Geophysics, V. 5, No. 2, pp. 121-172, May, 1967.

Tuttle, O. F., and N. L. Bowen, Origin of Granite in the Light of Experimental Studies in the System $\mathrm{NaAlSi}_{3} \mathrm{O}_{8}-\mathrm{KAlSi}_{3} \mathrm{O}_{8}-\mathrm{SiO}_{2}-\mathrm{H}_{2} \mathrm{O}$, Geol. Soc. America, Memoir 74, 1958.

Alfven, H., The Early History of the Moon and the Earth, Icarus, V. 1, pp. 357$363,1963$.

Lowman, P. D., Jr., Lunar Impact Craters, in The Encyclopedia of Atmospheric Sciences and Astrogeology, R. W. Fairbridge, Ed., Reinhold Publishing Company, New York, 1967.

Lorell, J., and W. L. Sjogren, Lunar Gravity: Preliminary Estimates from Lunar Orbiter, Science, V. 159, No. 3815, pp. 625-627, 9 Feb. 1968.

Baldwin, R. B., The Measure of the Moon, University of Chicago Press, Chicago, 1963.

Lowman, P. D., Jr., Space Panorama, WELTFLUGBILD Reinhold A. Muller, Feldmeilen/Zurich, Switzerland, 1968. 
Jeffreys, H., The Resonance Theory of the Origin of the Moon, II, Monthly Notices, Royal Astronomical Society, V. 91, p. 169, 1930.

MacDonald, G. J. F., Calculations on the Thermal History of the Earth, Jour. Geophys. Res., V. 64, pp. 1967-2000, 1959.

Dana, J. D., A General Review of Geological Effects of the Earth's Cooling from a State of Igneous Fusion, Art, XI, The American Journal of Science and Arts (now American Journal of Science - P. D. L.), Second Series, V. IV, pp. 88-92, 1847.

Shoemaker, E. M., The Geology of the Moon, Scientific American, V. 211, No. 6, pp. 38-47, Dec. 1964.

Gast, P. W., Implications of the Surveyor V Chemical Analysis, Science, V. 159, No. 3817, p. 897, 23 Feb. 1968.

McCauley, J. F., The Nature of the Lunar Surface as Determined by Systematic Geologic Mapping, in Mantles of the Earth and Terrestrial Planets, ed. by S. K. Runcron, Interscience Publishers, New York, 1967.

Hamilton, W., and W. B. Myers, The Nature of Batholiths, pp. C1-C30, in Shorter Contributions to General Geology, Geological Survey Professional Paper 554-C, Washington, D. C., 1967.

Gastil, G., The Distribution of Mineral Dates in Time and Space, Am. Journal of Science, V. 258, pp. 1-35, Jan. 1960. 
Hurley, P. M., H. W. Fairbairn, and W. H. Pinson, Jr., Radioactive Decay of $\mathrm{Rb}_{87}$ to $\mathrm{Sr}_{87}$ in Geological Science Exclusive of Age Dating, pp. 191-193 in Variations in Isotopic Abundances of Strontium, Calcium, and Argon and Related Topics, M. I. T. 1381-13, Thirteenth Annual Progress Report for 1965, U. S. Atomic Energy Commission Contract AT(30-1) 1381, Mass. Inst. of Technology, Cambridge, Mass., 1 December 1965.

Matsumoto, T., Some Aspects of the Formation of Primary Granitic Magmas in the Upper Mantle, in The Upper Mantle Symposium, New Delhi, 1964, ed. by C. H. Smith and T. Sorgenfrei, International Union of Geological Sciences, Det. Berlingske Bogtrykkeri, Copenhagen, 1965.

Ringwood, A. E., and D. H. Green An Experimental Investigation of the GabbroEclogite Transformation and Some Geophysical Implications, pp. 61-103, in Petrology of the Upper Mantle - High Pressure Experimental Investigations into the Nature of the Mohorovicic Discontinuity, the Mineralogical and Chemical Composition of the Upper Mantle and the Origin of Basaltic and Andesitic Magmas, Publication No. 444, Department of Geophysics and Geochemistry, Australian National University, Canberra, Australia, Aug. 1966.

Mason, B., Meteorites, Wiley, New York, 1962. 